\title{
Stress urinary incontinence treatment: Focus should be on identifying best candidates for surgical success in the first place
}

\author{
Shawna Johnston, MD \\ Department of Obstetrics and Gynecology, Queen's University, Kingston, ON, Canada
}

Cite as: Can Urol Assoc J 2017;11 (8):281-2. htrp://dx.doi.org/10.5489/cuaj.4801

See related article on page 275.

U rinary incontinence in females is common, with a reported prevalence in community-dwelling women estimated to be as high as $16 \% .^{1}$ Stress urinary incontinence (SUI) is the most common presentation. For most symptomatic women, quality of life is impaired, as SUI causes significant personal and financial burden. We can expect to see ever-increasing numbers of women as our Canadian population ages and as the prevalence of established risk factors for incontinence in women increase, including obesity, diabetes, and smoking. As the providers of care for these incontinent women, we are obliged to continue to search for the most effective and durable treatment options and ensure that what is offered is safe. Remember our oath: first, do no harm.

Management options include both non-surgical and surgical approaches. In general, non-surgical strategies should first be tried and surgery offered only in the context of nonsurgical treatment failure. The problem is that surgery works better, and patients are motivated to choose options that work. Behaviour modification (with bladder drill), weight loss, and pelvic floor muscle therapy require patience and perseverance, qualities unfortunately not found in all patients, and access to such options is sometimes problematic. Pessaries offer reasonable success, but not all women can be fitted with a pessary and ongoing pessary care can be onerous. Results from periurethral bulking to date are inferior to those reported with surgery. ${ }^{2}$ Few would argue that surgery is the mainstay for SUI treatment, but the critics still challenge the safety of this surgery and thus its positioning as the best treatment option available.

Management options have come a long way since the anterior repair was first described by Howard Kelly in 1900. In fact, more than 200 surgical procedures have been described. For many years, the gold standard surgery for SUI was the open Burch colposuspension. ${ }^{3}$ The 2002 landmark randomized controlled trial by Ward and Hilton ${ }^{4}$ challenged that standard by reporting equal subjective and objective cure rates with the Burch procedure and the novel tension-free vaginal tape (TVT) procedure, a minimally invasive midurethral sling (MUS) of synthetic mesh placed via the retropubic route without the need for laparotomy. A veritable flood of trials ensued, all documenting the durable efficacy and safety of the MUS procedure. Systematic reviews in time followed with their conclusions favouring the MUS procedure. ${ }^{5}$ The gold standard was replaced, and the MUS procedure worldwide became the surgery of choice to manage female SUI.

Synthetic midurethral slings seemed initially to offer the perfect solution - durable efficacy with minimal intervention and recovery time and low complication rates. Enthusiasm for the procedure grew, as did research effort. Mesh was inserted retropubically and later via the transobturator route. The mesh was varied by suture material, filament size, and pore size. The sling mesh was made somewhat adjustable via tensioning sutures. The procedure was even modified to be a single-incision mini-sling. But then mesh complications reared their ugly head. These included mesh exposure and/or erosion, infection, chronic pain, and dyspareunia. Relative panic ensued, and MUS procedures declined. The blush was off the rose.

The study by Ben-Zvi et al in this issue adds to the already large body of data focusing on MUS mesh safety. The authors report on both the efficacy and safety of a non-randomized cohort of 128 women undergoing MUS surgery with one of two synthetic meshes: polypropylene mesh (retropubic TVT or transobtuator TVT) or an in-house two-layer polypropylene-polytetrafluoroethylene mesh with smaller pore size thought to minimize adhesion formation (retropubic Composix ${ }^{T M}$ sling). Although the study has some important methodological flaws, all groups did have similar significant subjective and objective improvement or cure after surgery. Importantly, the mesh complication rate in the Composix group was higher, more than double the rate seen in the two other groups. The authors conclude that the Composix 
sling cannot be recommended for the MUS procedure. In fact, the point of this recommendation is questionable, as Composix mesh was actually recalled from the Canadian market during the trial.

So where are we now? We now know that while the synthetic MUS procedure is a highly effective treatment option for SUI, complications from synthetic mesh occur. We are still searching for the ideal sling material to mitigate these risks. Perhaps the pursuit is illogical, motivated now more by fear and medicolegal interest than clinical relevance. The prevalence of a synthetic mesh complication requiring removal of the sling, whether inserted via the retropubic or the obturator route, is low even over many years, estimated by investigators as less than $4 \% .{ }^{6}$ Can it really get much better? Is that elusive "no complication" mesh out there? It is unlikely.

In my humble opinion, we should focus our future research efforts not on finding better sling mesh, but rather on better understanding what preoperative patient criteria reliably identify surgical failure or success. Body mass index and age may be factors, but the research remains limited and unclear. There are probably other important individual biological, demographic, and comorbid patient factors still to be identified. We also lack robust tools to predict the success of non-surgical management for the individual patient, which leaves us unable to confidently recommend it first, above surgery, when a woman presents with bothersome incontinence. MUS surgery outcome is likely more dependent on these patient factors than on minor differences in sling material or pore size.
We have come a long way indeed in the surgical management of female incontinence. MUS surgery has dramatically improved our ability to care for incontinent women and concerns over sling safety should not overshadow this. While we continue to hunt for the ideal mesh, we should also hunt for the ideal patient in whom to implant it. Our surgeries will be more effective and safe when we understand who the best candidates for surgical success are in the first place.

Competing interests: The author reports no competing personal or financial interests.

\section{References}

1. Nygaard I, Barber M, Burgio KL, et al. Prevalence of symptomatic pelvic floor disorders in U.S. women. JAMA 2008:300:1311-6. https://doi.org/10.1001/jama.300.11.1311

2. Mamut A, Carlson KV. Periurethral bulking agents for female stress urinary incontinence in Canada. Can Urol Assoc J 2017:11:S152-4. https://doi.org/10.5489/cuaj.4612

3. Cox A, Herschorn S, Lee L. surgical management of female SUI: Is there a gold standard? Nat Rev Urol 2013;10:78-9. https://doi.org/10.1038/nrurol.2012.243

4. Ward K, Hilton P. Prospective, multicentre, randomized trial of tension-free vaginal tape and colposuspension as primary treatment for stress incontinence. BMJ 2002;325:67-70. https://doi.org/10.1136/ bmi.325.7355.67

5. Ogah J, Cody JD, Rogerson L. Minimally invasive synthetic suburethral sling operations for stress urinary incontinence in women. Cochrane Database Syst Rev 2009;7:CD006375. https://doi.org/10.1002/14651858.cd006375.pub2

6. Johsson Funk $M$, Siddiqui $N$, Pate $V$, et al. Sling revision/removal for mesh erosion or urinary retention: Long-term risk and predictors. Am J Obstet Gynecol 2013;73:el-7. https://doi.org/10.1016/i. ajog.2012.10.006

Correspondence: Dr. Shawna Johnston, Department of Obstetrics and Gynecology, Queen's University, Kingston, 0N, Canada; johnstos@KGH.KARI.NET

\title{
Urology locum in Nanaimo, BC
}

\author{
We are looking to recruit a Royal College of Physicians and \\ Surgeons of Canada-certified urologist to cover a community- \\ based general urology practice in Nanaimo, BC. It is a group office \\ practice with access to weekly operating room day and hospital- \\ based cystoscopy clinic.
}

The position is for four months, from April to July 2018.

$$
\begin{aligned}
& \text { Interested parties should send their information to } \\
& \text { kbmster@gmail.com. }
\end{aligned}
$$

